\title{
Interacciones entre SARS-CoV-2 y el sistema de defensas del aparato respiratorio: consideraciones para la prevención y el manejo de las infecciones
}

\author{
Interactions between $S A R S-C o V-2$ and the respiratory defense system: \\ considerations for the prevention and management of infections \\ José R. Cruz ${ }^{1 *}$ \\ ${ }^{1}$ Consultor Independiente
}

*Autor al que se dirige la correspondencia: jcruz62004@aol.com

Recibido: 23 de julio 2020 / Revisión: 15 de agosto 2020 / Aceptado: 03 de septiembre 2020

\section{Resumen}

Se describe la situación global de las infecciones por SARS-CoV-2 y los cuadros clínicos de COVID-19. Se presentan datos epidemiológicos de Centro América y de Guatemala, para ejemplificar algunos factores de riesgo de infección y morbilidad. Se revisa la función y estructura del sistema respiratorio, sus mecanismos de defensa innata -captura y remoción de agentes extraños, reconocimiento e inactivación de agentes potencialmente nocivos, reparación del daño y prevención de futuras incursiones por agentes identificados-, los de defensa adaptativa en las vías respiratorias y el microbioma. Se describen los tejidos linfoides nasal y bronquio-alveolar y la contribución de citoquinas, células especializadas y anticuerpos del tipo IgA secretoria a la protección antiviral, a la respuesta inflamatoria asociada a la infección y a la reparación del daño tisular. Se discuten las interacciones de SARS-CoV-2 con los mecanismos de defensa. Se presentan consideraciones para las medidas preventivas de infecciones, incluyendo la aplicación de vacunas, y para evitar enfermedad severa.

Palabras claves: SARS-CoV-2, COVID-19, sistema respiratorio, defensas innatas, inflamación

\begin{abstract}
$\mathrm{T}$ he global situation of SARS-CoV-2 infections and the clinical picture of COVID-19 are described. Epidemiological data from Central America and Guatemala are presented to exemplify some risk factors for infection and morbidity. The function and structure of the respiratory system and its innate defense mechanisms - capture and removal of foreign agents, recognition and inactivation of potentially harmful agents, repair of damage, and prevention of future incursions by identified agents - are reviewed, as are those of the adaptive defense in the airways and of the respiratory microbiome. The nasal and bronchioalveolar lymphoid tissues are described. The contributions of cytokines, of specialized cells and of secretory IgA-type antibodies to antiviral protection, to the inflammatory response associated with infection, and to the repair of tissue damage are explained. SARS-CoV-2 interactions with defense mechanisms are discussed. Considerations are presented for the preventive measures of infections, including the application of vaccines, and those designed to avoid severe disease.
\end{abstract}

Keywords: SARS-CoV-2, COVID-19, respiratory system, innate immunity, inflammation 


\section{Introducción}

La primera notificación internacional sobre la aparición en China de un brote de neumonía viral atípica, enfermedad ahora conocida como COVID-19, se recibió en la Organización Mundial de la Salud (OMS) el 31 de diciembre de 2019 (World Health Organization [WHO], 2020c). Una publicación del 24 de enero (Huang C. et al., 2020) indicó que en Wuhan había más de 800 casos confirmados por pruebas de ácido nucleico de un nuevo coronavirus y describió las características clínicas de 41 pacientes hospitalizados con tos, disnea, mialgia o fatiga. De ellos, 18 sufrieron complicaciones cardiacas, renales o supra infecciosas durante su hospitalización, 13 fueron admitidos a la sala de cuidados intensivos y seis fallecieron. El 25 de enero se dio a conocer que la causa de la enfermedad es un agente similar al coronavirus de murciélagos, por lo que fue nombrado 2019-Novel Coronavirus (Zhu et al., 2020) y luego clasificado como SARS-CoV-2 (International Committee for the Taxonomy of Viruses, 2020) debido a su relación genética con el agente etiológico del síndrome respiratorio agudo severo (SARS).

Los primeros casos de infección por el nuevo coronavirus fuera de China se identificaron durante las dos semanas iniciales de 2020 en Tailandia, Japón, Corea del Sur y Estados Unidos, en adultos que habían retornado de China con síntomas respiratorios leves (WHO 2020a, 2020c , 2020d; Centers for Disease Control and Prevention [CDC], 2020b), tanto así, que los Centros de Control y Prevención de Enfermedades de Estados Unidos (CDC) indicaron que la infección por SARS-CoV-2 posiblemente era de bajo riesgo para la población y con poca probabilidad de transmisión de humano a humano. Este tipo de contagio fue demostrado por observaciones epidemiológicas y análisis genéticos del virus en Hong Kong (Chan et al., 2020). Canadá fue el segundo país en América con casos de SARS-CoV-2, todos leves y en viajeros que llegaron de China en enero y de Irán y Egipto en febrero (Global News, 2020). A final de enero, 27 países habían confirmado infecciones por SARS-CoV-2, cifra que aumentó a 37 en febrero y a 151 en marzo (WHO, 2020b). El primer paciente guatemalteco fue identificado el 13 de marzo, a su regreso de España (Ministerio de Salud Pública y Asistencia Social [MSPAS], 2020a). Hasta el 1 de septiembre de 2020, el número de casos confirmados globalmente ascendía a 25,660,482, con el $24 \%$ de ellos diagnosticados en Estados Unidos y el 34\% adicional en Brasil, India y Rusia, mientras los países centroamericanos habían informado 302,131 infectados (Johns Hopkins University, 2020) (Tabla 1).

Un metaanálisis de estudios publicados demostró que $16 \%$ de las infecciones confirmadas pueden ser asintomáticas, con menor probabilidad, $8 \%$, en personas mayores (Byambusaren et al., 2020). Los infectados que no sufren síntomas pueden, al igual que los individuos presintomáticos, ser fuente de contagio para otras personas con quienes tienen contacto en su domicilio o en lugares aglomerados y con poca ventilación, incluyendo el transporte colectivo (He et al., 2020; Luo et al., 2020; Mizumoto et al., 2020; Nishiura et al., 2020; The City, New York, 2020).

El riesgo de transmisión de persona a persona es aún mayor cuando se realizan actividades grupales prolongadas, que producen jadeo, inducen a alzar la voz, o involucran cantar (CDC, 2020c; Dyal et al., 2020; Hammer et al., 2020; Jang et al., 2020). La exposición a individuos enfermos acarrea el riesgo extremo (Chou et al., 2020). A pesar de que el virus puede infectar el tracto gastrointestinal y la conjuntiva, se estima que la principal forma de contagio del SARS-CoV-2 es la respiratoria (Klompas et al., 2020). La carga de SARS$\mathrm{CoV}-2$ en el aparato respiratorio superior de quienes no muestran síntomas es comparable a la de aquellos que sí están enfermos (Arons et al., 2020; Cheng et al., 2020; Lavezzo et al., 2020).

Además de los asintomáticos, alrededor de $75 \%$ de quienes contraen SARS-CoV-2 sufren enfermedad leve que no requiere hospitalización. El análisis de los casos en China, Japón, Singapur, Corea del Sur, Italia y Canadá (Davies et al., 2020) mostró que la susceptibilidad a la infección por SARS-CoV-2 aumenta de $40 \%$ en los niños menores de 9 años, a $88 \%$ en las personas mayores de 60 y que la fracción de casos clínicos aumenta de $21 \%$ en los infectados menores de 19 años, a $69 \%$ en los mayores de 70 . El sexo y los grupos sanguíneos ABO influyen en la susceptibilidad al virus (Chen et al., 2020; Ellinghaus et al., 2020a, 2020b; Zhao et al., 2020; Zietz \& Tatonetti, 2020). En Guatemala, los hombres representan el 58\% de los casos y la incidencia de la infección varía en las cinco regiones sanitarias, de acuerdo con la prevalencia del grupo sanguíneo $\mathrm{O}$ (Tabla 2).

La COVID-19 fue originalmente reconocida como una neumonía atípica con base en su presentación clínica y en hallazgos radiológicos (Huang C. et al., 2020). Informes posteriores han establecido el cuadro general de infección respiratoria aguda causado por SARS-CoV-2 (Tabla 3) (Grant et al., 2020; 
Rodríguez-Morales et al., 2020; Siordia et al., 2020; Yang et al., 2020) y han puesto de manifiesto, además, que la pérdida del olfato y del gusto son signos comunes y útiles para la identificación temprana de casos (Menni, Sudre et al., 2020; Menni, Valdes et al., 2020) (Tabla 3).

La evolución de la pandemia, el acceso a pruebas virológicas de diagnóstico y la acuciosidad médica, han permitido reconocer que las infecciones por el SARSCoV-2 pueden afectar a los riñones, el hígado, el páncreas, el sistema cardiovascular, la piel y los nódulos linfáticos en adultos y en niños vulnerables (Agarwal et al., 2020; Ammirati \& Wang, 2020; De Giorgi et al., 2020; Hajifathalian et al., 2020; Lai et al., 2020; Li et al., 2020; Madjid et al., 2020; Ronco \& Reis, 2020; Sardanelli et al., 2020; Sultan et al., 2020; Szartmary et al., 2020; Zhang et al., 2020). De especial interés son el síndrome inflamatorio multisistémico parecido a la enfermedad de Kawasaki descrito en niños y adolescentes previamente sanos (CDC, 2020a; Feldstein et al., 2020; Riphagen et al., 2020; Toubiana et al., 2020; Verdoni et al., 2020; Viner \& Whitaker, 2020) y el daño neurológico central en adultos jóvenes (Divani et al., 2020; Zubair et al., 2020).

Indicadores bioquímicos que se han encontrado alterados en pacientes con COVID-19 incluyen recuentos de leucocitos, linfocitos, neutrófilos, plaquetas y tiempo de protrombina disminuidos y niveles de sedimentación globular, proteína $\mathrm{C}$ reactiva, ferritina, lactato deshidrogenasa, troponina, dímero $\mathrm{D}$ e interleucina 6 (IL-6) aumentados. La gama de severidad de la infección y del riesgo de muerte por SARS-CoV-2 están asociados a edad, sexo, índice de masa corporal, a la presencia de otras enfermedades crónicas en individuos y a características genéticas y factores ambientales en poblaciones (Domingo et al., 2020; Grant et al., 2020; Mustafa \& Selim, 2020; Pan et al., 2020; Rodríguez-Morales et al., 2020; Sharma et al., 2020; Y. Wu et al., 2020; Zhao et al., 2020; Zietz \& Tatonetti, 2020). Además, el acceso a servicios de salud, el diagnóstico temprano y la calidad de la atención médica determinan el resultado clínico de enfermedades respiratorias (Cruz et al., 1990), por lo que no es sorprendente que la mortalidad debida a COVID-19 varíe entre países y de acuerdo con la evolución local de la pandemia. Así, la tasa de letalidad, que a nivel global es 3.33\%, es superior a $7 \%$ en nueve naciones e inferior a $1 \%$ en 27 de las 172 que han reportado casos (Johns Hopkins University, 2020). La Tabla 1 resume la mortalidad en los países centroamericanos, listados en orden creciente de sus tasas de letalidad, las cuales fluctúan entre 1.1 y $3.7 \%$.

La interacción del SARS-CoV-2 con el sistema de defensas, especialmente a nivel del tracto respiratorio, define las manifestaciones clínicas de las infecciones, sus consecuencias tempranas y sus posibles complicaciones. Por lo tanto, es fundamental conocer y analizar dicha interacción para establecer intervenciones pertinentes dirigidas a prevenir la transmisión del virus, para cuidar a los pacientes infectados y para evitar futuros brotes en la comunidad.

\section{Contenido}

\section{El sistema respiratorio}

Según Patwa y Shah (2015), la función principal del sistema respiratorio en el humano es proporcionar oxígeno a todas las células del cuerpo y eliminar el dióxido de carbono que ellas producen como resultado de su metabolismo energético. Para ello, el sistema respiratorio trabaja en íntima relación con el sistema circulatorio y en respuesta a los procesos metabólicos a nivel celular. Además de promover el flujo sanguíneo y linfático, el sistema respiratorio también ayuda a mantener el balance ácido-base del cuerpo y juega un papel central en el olfato, la vocalización y el habla. El oxígeno se encuentra en menor proporción (21\%) que el nitrógeno (78\%) en el aire atmosférico, el cual contiene también argón, dióxido de carbono, neón, helio, metano, hidrógeno y vapor de agua. La temperatura ambiental y la presión atmosférica varían entre los lugares del planeta y a través del tiempo, en cada uno de los diferentes sitios. Por ello, el sistema respiratorio debe adaptarse a las condiciones locales y a las propias del individuo, de tal forma que se mantengan a nivel pulmonar la temperatura y los gradientes de presión que garanticen el intercambio permanente de gases y el balance sistémico de oxígeno y dióxido de carbono, de acuerdo con el nivel metabólico individual. Así, los recién nacidos, los adultos entre 51 y 60 años y las personas mayores de 81 inhalan, en promedio diario, $6.00,13.14$ y $9.13 \mathrm{~L}$ de aire/min, respectivamente. Estas cantidades, ajustadas por horas de dormir y de actividad física leve, moderada y alta, corresponden a 8,640, 18,922 y 13,147 L de aire inhalados en un día a cada uno de los grupos etarios mencionados (United States Environmental Protection Agency, 2009). 
Tabla 1

Número de casos de COVID-19, incidencia (por 100,00 habitantes), tasa de letalidad (\%) y tasa de mortalidad (por 100,000 habitantes) en los países de Centro América, hasta el 14 de julio de 2020

\begin{tabular}{lllllll}
\hline \multirow{2}{*}{ País } & \multicolumn{2}{c}{ Casos } & Muertes & & $\begin{array}{c}\text { Letalidad } \\
\left(\text { Puesto }^{1}\right)\end{array}$ & $\begin{array}{c}\text { Mortalidad } \\
\left(\text { Puesto }^{2}\right)\end{array}$ \\
\cline { 2 - 3 } & Número & Incidencia & & & & \\
Costa Rica & 42,184 & 847.46 & & 443 & $1.1(35)$ & $8.72(112)$ \\
Panamá & 93,552 & $2,503.43$ & 2.018 & $2.2(86)$ & $47.93(152)$ \\
El Salvador & 25,820 & 403.48 & 724 & $2.8(108)$ & $11.17(119)$ \\
Nicaragua & 4,668 & 72.34 & 789 & $3.0(111)$ & $2.12(64)$ \\
Honduras & 61,014 & 636.89 & & 1,873 & $3.1(123)$ & $19.54(136)$ \\
Guatemala & 74,893 & 434.42 & 2,778 & $3.7(133)$ & $16.00(127)$ \\
\hline & Todos & 302,131 & 618.37 & 7,977 & 2.6 & 16.32 \\
\hline
\end{tabular}

Nota. ${ }^{1}$ Puesto, de menor valor a mayor, entre 172 países/territorios. ${ }^{2}$ Puesto, de menor valor a mayor, entre 164 países /territorios. https://coronavirus.jhu.edu/map.html

En el humano, la nariz está dividida por el tabique en dos fosas nasales, cada una de las cuales esta subdividida en pasajes angostos por los cornetes. Esta estructura produce pequeñas turbulencias, aumenta el área superficial neta de mucosa nasal y maximiza el tiempo de tránsito de manera que todo el aire inhalado se humedezca, caliente y filtre en preparación para su llegada a las vías respiratorias inferiores. Debajo del epitelio del cornete central se localizan folículos linfoides, que se conocen como tejido linfoide nasal (NALT) (Randall, 2015). Para funcionar adecuadamente, los cornetes tienen abundante inervación, que los hace sensibles a cambios de temperatura externa, y rica irrigación sanguínea, que les permite ajustar su producción de fluidos para humedecer todo el aire que los cruza y para facilitar la producción y acción del moco. Estas funciones son tan importantes que, en poblaciones, el ancho de la base y de las fosas nasales han evolucionado para adaptarse a factores climáticos determinantes de la temperatura y humedad ambientales (Zaidi et al., 2017).

La faringe, por su parte, une la nariz con la laringe y el esófago, marcando la separación de los sistemas respiratorio y digestivo. El aire y los alimentos pasan por la faringe y deben ser dirigidos hacia los pulmones y el estómago, respectivamente, por lo que su funcionamiento está íntimamente relacionado con el de la epiglotis. La nasofaringe, formada por músculos cubiertos por membrana mucosa, contiene las adenoides o amígdalas faríngeas que, a diferencia de otras amígdalas, contienen epitelio columnar pseudoestratificado. Las amígdalas palatinas, formadas por tejido linfoide, se encuentran en la orofaringe. Estos dos tipos de amígdalas, junto con las tubáricas y los cordones faríngeos laterales, conforman el anillo de Waldeyer (Randall, 2015).

La laringe, que marca la transición del aparato respiratorio superior a inferior, está formada principalmente por músculos y cartílagos revestidos por membrana mucosa y une a la faringe con la tráquea. La función de ésta es mantener permanentemente abiertas las vías respiratorias, por lo que es elástica, rica en cartílago y cubierta por epitelio pseudoestratificado con células secretoras y células ciliadas. Su lámina propia interior contiene tejido linfoide.

La tráquea se divide en dos bronquios que conservan su misma estructura cartilaginosa y epitelial, pero son ricos en tejido linfoide (BALT) diferente a NALT, al de la mucosa gastrointestinal (GALT) y a los nódulos linfáticos periféricos. Los bronquios entran a los pulmones, en donde continúan dividiéndose en canales sucesivamente más delgados y sin cartílago, hasta formar los alveolos pulmonares. Las paredes de los alveolos están formadas por neumocitos tipo I, células planas en una monocapa que permite el intercambio gaseoso entre el aire inhalado y la sangre, y por neumocitos tipo II, células secretoras tipo cuboideo que producen el surfactante pulmonar. Los macrófagos se encuentran en los espacios intersticiales o en el interior de los alveolos (Garrett el al., 2019). Una característica 
común del epitelio respiratorio son los empalmes intercelulares que están en la superficie apical y que permite a las células formar una muralla hermética. Los empalmes están formados por piezas que se ajustan mutuamente y pueden controlar la permeabilidad epitelial. La unión superior está compuesta por proteínas que forman cintas oclusoras (ZO) identificadas como ZO-1, ZO-2 y ZO-3, en combinación con ocludinas, claudinas y moléculas transmembranas de adhesión. Inmediatamente abajo están las uniones adherentes, compuestas por B-catenina y E-cadherina, que inician la proliferación y la diferenciación celulares. Un juego adicional de uniones de brecha, compuestas de conexinas, se sitúa a un nivel inferior (Invernizzi et al., 2020). Desbalances de esta estructura, causados por agentes químicos, físicos y biológicos, incluyendo microorganismos, pueden inducir disfunción en las defensas del aparato respiratorio (Gon \& Hashimoto, 2018 Rezaee et al., 2011).

\section{Defensas del sistema respiratorio}

El aire inspirado contiene, además de los gases mencionados, agentes físicos, químicos y biológicos, incluyendo microorganismos, algunos potencialmente nocivos para el humano. En contraste con la mucosa intestinal, que su protección primaria contra estos agentes es el ácido gástrico, la protección de primera línea de la mucosa respiratoria depende del moco, producido en las glándulas submucosas por las células secretoras (Fahy \& Dickey, 2010; Hiemstra et al., 2015). La mayoría de los microorganismos y las partículas mayores a $10 \mu \mathrm{m}$ que ingresan en el aire inhalado son atrapados por el moco en el tracto respiratorio superior y expulsados rápidamente por el movimiento de cilios en la superficie de células cilíndricas localizadas en el estrato superior de la membrana (Schuster et al., 2013).

Las partículas de tamaño intermedio, 2-10 $\mu \mathrm{m}, \mathrm{y}$ los microorganismos que logran sobrepasar el aparato respiratorio superior, pueden ser detenidos por el moco en el aparato respiratorio inferior y eliminados cuando las células ciliadas lo impulsan hasta la faringe y es expulsado por la tos o por un proceso de deglución inadvertido (Garrett et al., 2019). Aquellos agentes que logran alcanzar los alveolos pueden ser capturados por macrófagos alveolares (AM), que constituyen la última línea de defensa pulmonar, pero su eliminación del ambiente pulmonar toma periodos prolongados (Stark et al., 2006). Los macrófagos y las células dendríticas (DC) del aparato respiratorio pueden participar en el establecimiento de la inmunidad adaptativa, específica contra un agente extraño determinado, en colaboración con células linfoides residentes en adenoides, amígdalas e intersticio bronquial y con aquellas que son reclutadas de la sangre. Algunos microorganismos que evaden los procesos de captura y eliminación fisicoquímica o fagocítica inicial, o por anticuerpos y linfocitos específicos, en una etapa posterior, pueden causar enfermedad o pasar a formar parte del microbioma de los pulmones y contribuir al balance biótico (Zaidi et al., 2017).

\section{Respuesta inmune innata en las vías respiratorias}

Por la permanente exposición al ambiente externo que el sistema respiratorio tiene, la implementación de su primera línea de defensa está diseñada para: (a) capturar y remover agentes extraños; (b) reconocer agentes extraños potencialmente nocivos; (c) inactivar a los agentes extraños potencialmente nocivos; (d) promover la reparación del daño que esos agentes pudiesen haber causado; y, (e) promover la prevención de futuras incursiones por dichos agentes (Kato \& Scheiemer, 2007; Weber, 2020).

Captura y remoción de agentes extraños: $\mathrm{La}$ maquinaria para capturar y remover agentes extraños que llegan a las vías respiratorias está constituida por el líquido superficial de las vías aéreas (ASL) y por las células ciliadas. El ASL, a su vez, consta de dos capas. La capa superior de moco, de alta viscosidad por su contenido de mucinas, principalmente MUC5AC y MUC5B, es producida por las células caliciformes. El moco protege al epitelio respiratorio, captura a las partículas y microorganismos extraños, transporta substancias protectoras producidas por células epiteliales y provee un medio que puede ser empujado hacia la faringe por los cilios. La capa inferior, el gel pericilar (PCG), de menor viscosidad por su contenido de MUC1 y MUC4 y otras glicoproteínas, permite la libre oscilación de los cilios y, por lo tanto, la expulsión del moco que contiene a los agentes extraños capturados. La velocidad de expulsión de moco es determinada por las células epiteliales que actúan como sensores de cambios en la carga mecánica de la respiración, expresada por el flujo de aire, la extensión de las vías respiratorias y la presión a sus paredes, regularmente asociados a ejercicio físico, tos y dificultad respiratoria. 
La mayor velocidad de expulsión de moco requiere mantener su nivel de hidratación, ya que el agua constituye su 97\% (Fahy \& Dickey, 2010; Zanin et al., 2016).

Reconocimiento e inactivación de agentes potencialmente nocivos: La inactivación de agentes potencialmente nocivos en las vías respiratorias del humano es la expresión de un proceso atávico de protección biológica muy primitivo (Khan et al., 2020). Los organismos vivos reconocen patrones moleculares extraños a los propios y subsecuentemente producen substancias antagónicas que inactivan a las moléculas reconocidas como intrusas y probablemente nocivas. La producción por hongos de compuestos antibacterianos, como la penicilina, y la elaboración por las bacterias de enzimas, como las penicinilasas que inactivan a esos antibacterianos, son ejemplos clásicos de la existencia ancestral del proceso de reconocimiento de patrones moleculares ajenos a los propios y de la respuesta protectora contra ellos (Davies \& Davies, 2016).

En las vías respiratorias, la detección de agentes extraños o de células propias dañadas se inicia por receptores que reconocen patrones moleculares (PRR) diferentes a los normales propios (Takeuchi \& Akira, 2020). Los PRR incluyen cuatro familias de receptores.

La primera está constituida por 10 receptores tipo Toll (TLR), expresados en células epiteliales, macrófagos, leucocitos, células dendríticas y linfocitos. Los TLR1, TLR2, TLR4, TLR5, TLR6 y TLR10 funcionan en la membrana celular, en donde reconocen patrones extraños de proteínas, lípidos, polisacáridos, ADN y ARN de doble cadena. Los TLR3, TLR7, TLR8 y TLR9 se encuentran endosomas y detectan ácidos nucleicos extraños después de su endocitosis. Sin embargo, los diferentes TLR pueden formar cadenas de uno o varios tipos, lo que amplía su sensibilidad y eficacia. Por ejemplo, TLR2 reconoce cubiertas virales y TLR3 identifica ARN viral de doble cadena. Ambos grupos de TLR transmiten, través de un segmento transmembrana, su señal activadora a un dominio receptor en el citoplasma, llamado receptor Toll/IL-1 (TIR). Éste actúa como plataforma intermediaria con un grupo de proteínas adaptadoras, tales como MyD88 y la inductora de interferón $\beta$ (TRIF), que inducen la transcripción de factores que coordinan la producción de péptidos antimicrobianos, proteínas antivirales, substancias quimiotácticas y mediadores de inflamación (Invernizzi et al., 2020). Los TLR en células dendríticas pueden inducir la diferenciación fenotípica de linfocitos $\mathrm{T}$ a linfocitos T auxiliares tipo 1 (Th1), que favorecen las respuestas protectoras (Berger, 2000).
La segunda familia de PRR son los similares al dominio de oligomerización de unión de nucleótidos (NOD), denominados NLR. Éstos se encuentran en el citosol de células epiteliales e inmunes y participan en la transcripción de proteínas del complejo mayor de histocompatibilidad, en la formación de fagosomas, en la apoptosis y en procesos inflamatorios. Se conocen 22 NLR humanos, algunos de los cuales activan la quinasa Rip2, la que a su vez activa NFkB, el complejo proteínico en el citosol que, al activarse, ingresa al núcleo celular y controla la transcripción de ADN y la producción de citoquinas. Otros NLR pueden promover la formación de inflamasomas, que median muerte celular y producción de IL-1B e IL-18 (Garrett et al., 2019).

La tercera familia incluye a los receptores similares al gen inducible por ácido retinoico (RIG), llamados RLR. Éstos son helicasas que reconocen patrones extraños de ARN. RIG-1 se une a 5'-tri y 5'difosfatos en moléculas cortas de ARN viral de doble cadena, mientras que MDA5 se une a ARN viral de doble cadena larga. Ambos operan a través del señalizador mitocondrial antiviral (MAVS), lo que lleva a la activación de IRF3/7 y a la consecuente producción de interferones tipo 1 y a la producción de citoquinas proinflamatorias mediadas por NFkB (Garrett et al., 2019).

La cuarta familia está compuesta por los receptores denominados CLR, que se unen a carbohidratos en un proceso mediado por calcio. Dos de ellos, Tipo I y II, están unidos a la membrana celular de macrófagos y células dendríticas, mientras el tercero es soluble. Todos los CLR están programados para reconocer componentes de hongos (Garrett et al., 2019; Invernizzi et al., 2020).

Reparación del daño y prevención de futuras incursiones por agentes identificados: Los PRR, además de reconocer patrones moleculares diferentes a los propios, tienen la capacidad de identificar patrones moleculares asociados a células dañadas (DAMP) (Amarante-Mendes et al., 2018). Las células epiteliales producen substancias que afectan la diferenciación de células residentes en las vías respiratorias, que promueven el reclutamiento de leucocitos del sistema circulatorio y que regulan las expresiones inflamatorias de todas ellas, induciendo linfocitos auxiliares del tipo 2 (Th2), los que favorecen las respuestas de reparación tisular (Berger, 2000). Así, las células secretorias pueden diferenciarse a células epiteliales ciliadas o no ciliadas. Las células basales pueden diferenciarse a caliciformes que presentan antígenos a las células dendríticas (DC). 
De éstas se reconocen tres subclases; dos mieloides, mDC-1 y mDC-2, y una plasmoide, pDC, con marcadores CD1, CD141 y CD123, respectivamente. Las DC pueden presentar antígeno a linfocitos residentes en los pulmones o reclutados del sistema circulatorio. Las DC123 pueden ser educadas por las células caliciformes diferenciadas para presentar antígenos (Kato \& Schieimer, 2007).

En resumen, una vez reciben la señal de un PRR, las células de las vías respiratorias se activan, producen y liberan factores de complemento, catelicidinas, colectinas, defensinas, lisozimas, interferón $\beta$, interferón $\lambda$, ficolinas y otras substancias que inhiben la división bacteriana y la replicación viral y que opsonizan o neutralizan microorganismos. Los microrganismos y sus desechos capturados por el moco son empujados hacia la laringe por el movimiento ciliar y eliminados al exterior en esputos o por deglución inadvertida hacia el sistema digestivo en alrededor de seis horas. Si los microorganismos alcanzan a causar daño a los tejidos, las células epiteliales reconocen los DAMP e inician la reparación celular. La respuesta inflamatoria es proporcional a las lesiones causadas al tejido propio. Por otro lado, células de las vías respiratorias participan en la educación de linfocitos auxiliares Th1 o Th2 o de linfocitos $\mathrm{T}$ de memoria, lo que inicia la respuesta inmune adaptativa específica (Berger, 2020; Garrett et al., 2019; Invernizzi et al., 2020).

\section{Respuesta inmune adaptativa en las vías respiratorias}

Cuando los mecanismos de defensa innata en las mucosas reconocen agentes extraños que representan una amenaza permanente o potencialmente letal para el individuo, recurren a las defensas sistémicas, de tal forma que el organismo pueda eliminar completamente a dichos agentes y prevenir sus futuras incursiones al organismo. La respuesta inmune que alcance esos objetivos, sin embargo, debe permitir el funcionamiento óptimo del sistema respiratorio y ser complementaria a las defensas innatas. Por esa razón, el NALT y el BALT, diferentes entre sí, actúan en coordinación con GALT (Lambrecht et al., 2015; Silva-Sánchez \& Randall, 2020).

El NALT está localizado debajo del epitelio de cornete central y formado por pequeños folículos de células linfoides. El número y tamaño de los folículos depende de los estímulos antigénicos e inflamatorios a los que el individuo ha estado expuesto durante su vida (Debertin et al., 2003). El centro de cada folículo contiene linfocitos B rodeados de linfocitos T, los cuales también ocupan los espacios entre los folículos. Las DC comparten espacio con los linfocitos T y, además, están inmediatamente abajo del epitelio del cornete, en un área en donde es altamente probable que encuentren antígenos que entran por las vías nasales. El epitelio por encima de las DC, la cúpula subepitelial, contiene células con multiplicidad de pliegues, las células M, con capacidad de transportar antígenos solubles y particulados, incluyendo virus, y presentarlos a los linfocitos B y a las DC adyacentes. La composición celular de NALT depende de la interacción específica entre distintas citoquinas y sus receptores (Garrett et al., 2019; Randall, 2015).

Las vénulas endoteliales y canales linfáticos eferentes permiten el reclutamiento y asentamiento de células de la circulación sanguínea y la emigración de células educadas hacia nódulos linfáticos cervicales, respectivamente. La estructura celular y vascular de NALT facilita que las células M acarreen organismos inocuos contra los cuales es conveniente inducir una respuesta no inflamatoria a nivel de todas las mucosas. NALT produce el factor transformador de crecimiento B (TGF-B) que induce la expresión de linfocitos $\mathrm{T}$ CD4, la producción de IgA por linfocitos $\mathrm{B}$ y la inhibición de NFkB, el inductor nuclear de citoquinas. Adicionalmente, NALT libera IL-10, citoquina inhibidora de la producción de IL-6 y de otros mecanismos inflamatorios. Sin embargo y a diferencia de GALT, si el reto antígeno es acompañado de un adyuvante, NALT responde también con linfocitos B productores de IgG, con linfocitos T CD4 y secretores de interferón Y (Randall, 2015). Este tipo de inmunización nasal resulta en linfocitos B de memoria productores de anticuerpos IgA de mayor afinidad que los IgG homólogos. Por otro lado, la respuesta inmune de NALT incluye linfocitos T CD8 citotóxicos y de memoria que, además de persistir en el tejido nasal, migran a los pulmones, a las glándulas salivales y a los intestinos (Invenizzi et al., 2020). El hecho que el número de folículos de NALT en cada individuo dependa de retos antigénicos indica que la existencia de NALT no es vital para la protección de la mucosa nasal. Experimentos en animales han demostrado que, en ausencia de NALT, la inmunización directa de los nódulos linfáticos cervicales da lugar a una respuesta inmune nasal idéntica a la descrita arriba (Wiley et al., 2005).

El BALT es otro tejido linfoide cuya formación depende de infecciones o procesos inflamatorios. BALT consiste en folículos grandes, con linfocitos 
$\mathrm{B}$, células plasmáticas, linfocitos T, DC foliculares y macrófagos, localizados debajo de la cúpula subepitelial en las vías respiratorias mayores y en folículos pequeños o grupos reducidos y dispersos de linfocitos $\mathrm{B}$ únicamente. Los folículos están tránsito conectados a vénulas y a canales linfáticos, con estructura y función similar a NALT que, dependiendo de las características antigénicas que los indujeron, pueden contener eosinófilos y neutrófilos. Los tipos de células linfoides reclutadas de la sangre dependen de citoquinas especializadas que dirigen el tránsito hacia BALT, especialmente de IL-17, que es producida por células epiteliales y por linfocitos $\mathrm{T} \gamma / \delta$ intraepiteliales. IL-17 actúa durante la formación de BALT, en la fase inflamatoria aguda (Zhu \& Fu, 2012).

La estructura celular del folículo es posteriormente definida por interacciones entre linfocitos, DC y células subepiteliales. Estas interacciones son vitales para la respuesta adaptativa, ya que no todo BALT tiene células M, como las descritas para NALT. BALT tiene canales linfáticos eferentes que pueden acarrear antígeno. Las DC también pueden capturar antígenos en las vías respiratorias y luego migrar a BALT atravesando el epitelio o por los canales linfáticos. Otra posibilidad de encontrar antígeno es la formación de BALT en contacto físico, directo, con el sitio mismo de infección, especialmente cuando agentes virales infectan linfocitos B en forma latente (Garrett et al., 2019; Randall, 2015).

Independientemente de la forma de exponerse a antígenos, BALT es capaz de iniciar y mantener respuestas especificas por linfocitos B y linfocitos T. En contraposición a NALT, en BALT predomina la respuesta mediada por IgG sobre la IgA. Sin embargo, las células plasmáticas que producen IgG migran preferentemente a la médula ósea, mientras que aquellas que producen IgA se instalan primordialmente en los pulmones. Ambos tipos de células plasmáticas regularmente mantienen anticuerpos específicos neutralizantes en plasma por periodos prolongados y en títulos suficientes para prevenir infecciones posteriores. Dependiendo de la naturaleza del antígeno, BALT también produce anticuerpos IgE. En general, BALT inicia respuestas inmunes más rápidas y protectoras que las iniciadas en otros sitios sistémicos (Garrett et al., 2019; Randall, 2015). De especial interés son los linfocitos Th 17 específicos contra M. tuberculosis inducidos por vacunación que, cuando posteriormente son expuestos a la bacteria, promueven la pronta y eficiente activación de macrófagos y el control de la infección (Lyadova \& Pataleev, 2015).
Las DC son indispensables para inducir una respuesta inmune específica contra células infectadas por un virus determinado. Las células epiteliales, activadas por la señal de TLR que reconocen moléculas virales, producen factor estimulante de colonias de granulocitos (GM-CSF), linfopoyetina estromal tímica (TSLP) e IL-1, los que inducen la diferenciación de monocitos a DC presentadoras de antígeno y a macrófagos alveolares. Las DC, por su parte, poseen PRR y responden produciendo IL-1. Ésta resulta en la inducción de linfocitos T CD8 citotóxicos específicos en los nódulos linfáticos y en la eliminación del virus. Sin embargo, la inflamación resultante puede causar daño pulmonar, complicaciones severas y muerte (Lin et al., 2008).

Los mecanismos de eliminación de células infectadas por virus respiratorios incluyen la lisis por la cascada de complemento, mediada por anticuerpos IgM e IgG, pero no por IgA, la fagocitosis post opsonización y la citotoxicidad celular dependiente de anticuerpos (ADCC). En esta última participan anticuerpos IgG, aun cuando ellos no neutralizan al virus y células asesinas, que reconocen anticuerpos unidos a las células infectadas (Jegaskanda, 2013).

Los macrófagos, las células M y las DC presentan los antígenos a linfocitos $\mathrm{T}$ auxiliares, que inducen la maduración de linfocitos $\mathrm{T}$ citotóxicos y de memoria, así como de células plasmáticas productoras de anticuerpos específicamente dirigidos a los antígenos presentados. Los anticuerpos predominantes y funcionales en las mucosas son del tipo $\operatorname{IgA}$ secretoria (SIgA) y resultado de la cooperación entre células linfoides, que producen inmunoglobulina y las células epiteliales, que producen el receptor de inmunoglobulina polimérica (pIgR), originalmente conocido como "componente secretorio". El pIgR es una proteína transmembranosa en las células epiteliales que se une a dímeros de IgA por su fracción cristalizable $(\mathrm{Fc})$, los exporta al lumen de las vías respiratorias y les concede resistencia contra las enzimas proteolíticas. Los anticuerpos SIgA específicos pueden inmovilizar e inactivar bacterias, virus, toxinas y alergenos. Los complejos SIgA/ antígeno pueden ser capturados por las células $\mathrm{M}$ que, al presentarlos a linfocitos $\mathrm{T}$, inducen tolerancia de los brazos Th1 y Th2 de la respuesta inmune sistémica. Además, los residuos de manosa en las moléculas de SIgA pueden unirse a bacterias de variadas especies e inhibir su adhesión a células epiteliales. Los complejos SIgA/bacterias inhiben la producción de citoquinas proinflamatorias, como IL-6 e interferón $\gamma$, en las células fagocíticas (Mantis et al., 2011). Estos dos mecanismos contribuyen a la "exclusión microbiana" 
de las vías respiratorias, por un lado, y a mantener la homeostasis del microbioma respiratorio, por otro (Corthésy, 2013; Garrett et al., 2019).

\section{Homeostasis del microbioma respiratorio}

A pesar de los diferentes mecanismos de defensa, tales como las barreras presentadas por la estructura del epitelio respiratorio, la composición química del moco, la función antimicrobiana inducida por PRR, y la capacidad fagocítica de células residentes, las vías respiratorias se encuentran habitadas por microorganismos, principalmente bacterias, que no causan daño alguno y que no están sujetos a los mecanismos de defensa innata y adaptativa del aparato respiratorio (Hanshew et al., 2017). Estos microorganismos llegan a las vías respiratorias en el aire inhalado, por micro aspiración y por dispersión. Su composición y número están determinados por la carga inicial de entrada, por la habilidad de reproducirse in situ y por su tasa de eliminación (Garrett et al., 2019). Procesos inflamatorios causados por contaminantes químicos y por infecciones modifican las condiciones locales en las vías respiratorias inferiores y en los pulmones, favoreciendo la reproducción selectiva de algunas especies y el desbalance del microbioma, situación conocida como disbiosis (Petersen \& Round, 2014). La disbiosis, a su vez, agrava la inflamación, promueve mayores daños estructurales y funcionales que pueden llegar a causar la muerte. Cambios en la composición del microbioma, especialmente la contaminación pulmonar con especies bacterianas supraglóticas induce inflamación alveolar que puede ser severa (Segal et al., 2013).

\section{Interacciones del SARS-CoV-2 con el sistema de defensas de las vías respiratorias}

A pesar de que el material genético de SARSCoV-2 se ha detectado en orina, semen, lágrimas, heces y sangre (Gupta et al., 2020) y que al momento de escribir este artículo todavía no se conoce a ciencia cierta la contribución de los aerosoles en su propagación, se considera que la fuente principal de contagio con el SARS-CoV-2 son las vías respiratorias de personas infectadas (Klompas et al., 2020). Los vehículos que transportan partículas virales a un nuevo hospedero y las formas en que ellas alcanzan tejidos en donde pueden replicarse, parecen determinar el curso clínico de la nueva infección, incluyendo el tiempo de incubación.
La transmisión a través de objetos inanimados, que originalmente fue considerada como única modalidad, depende de la llegada de fluidos respiratorios a las manos de los infectados, de su traslado sucesivo a objetos y superficies accesibles a individuos no infectados y posteriormente a sus manos, ojos, nariz o boca. La transmisión de persona a persona parece depender de la exposición sostenida a partículas virales activas que el infectado emite por vía nasal o bucal y que llegan a la conjuntiva, nariz o tráquea del nuevo hospedero (Hui et al., 2020). En ambos casos, la infección de la conjuntiva probablemente resulta en infección nasal, a través de los senos paranasales y sujeta a las barreras de defensa y acción de NALT. La replicación viral en tejidos nasales, demostrada por la infección de tejido epitelial y olfatorio (Brann et al., 2020; Sungnak et al., 2020), favorece la producción de anticuerpos del tipo SIgA, la reducción significativa de la carga viral y la protección de mucosas distantes (Pabst et al., 2016). Se ha demostrado que la carga viral de SARS-CoV-2 es mayor en la nariz que en la garganta de pacientes enfermos y de individuos asintomáticos (Zou et al., 2020).

La infección por la vía bucal que ocurre durante conversaciones prolongadas, al cantar o al jadear, conlleva la inspiración profunda de aire contaminado por SARS-CoV-2 y el acarreo de virus activo directamente a la tráquea y a los alveolos, tránsito que elimina la exposición viral a los tejidos linfáticos del anillo de Waldeyer. La tráquea y los alveolos, en donde la respuesta de anticuerpos específicos por BALT es predominantemente del tipo $\mathrm{IgG}$, son el sitio preferido para la replicación de SARS-CoV-2, demostrado por las mayores cargas virales en esputo y aspirados traqueales, que en garganta y nariz de pacientes críticos (Huang Y. et al., 2020) y por infecciones experimentales in vitro (Hui et al., 2020). SARS-CoV-2 infecta células ciliadas, células caliciformes y células cuboidales en el epitelio bronquial, en forma similar que la observada con MERS-CoV, pero alcanzando títulos menores a los del virus pandémico de influenza H1N1 durante las primeras 48 horas post infección (Hui et al., 2020). Sin embargo, SARS-CoV-2 aumenta su tasa de replicación en los bronquios durante las siguientes 48 horas, alcanzando su máximo nivel a las 96 horas.

Esta secuencia de actividad replicativa probablemente sea debida a los cambios metabólicos que SARS-CoV-2 es capaz de inducir en las células infectadas. En primer lugar, para evadir el reconocimiento por TLR, los coronavirus inducen la formación en el citoplasma celular de organelas de replicación, que son vesículas cubiertas por doble membrana, en donde el 
ARN viral es fabricado sin ser detectado e identificado como extraño. Además, como una medida agregada de seguridad, SARS-CoV-2 recurre al "mimetismo" con la metilación de sus ARN intermedios y de esa forma evade su identificación por MDA5 y la consecuente activación de la respuesta inmune innata (Kikkert, 2020). SARS-CoV-2 induce bajos niveles de citoquinas durante la fase inicial de replicación. COVID-19 severa ha sido asociada a respuestas deficientes de DC y linfocitos T CD8 durante las primeras tres semanas post infección, aun en la presencia de altos niveles de anticuerpos neutralizantes (Zhou et al., 2020). En estas condiciones, es muy probable que los nuevos viriones de SARS-CoV-2 producidos en el tejido traqueobronquial lleguen a los espacios alveolares, en donde infectan neumocitos tipo 1 (Hui et al., 2020). Estas células son vitales para el intercambio de gases en los alveolos y para prevenir la extravasación de líquido hacia el espacio alveolar. SARS-CoV-2 también infecta neumocitos tipo 2 (Hou et al., 2020). Por otro lado, el arribo de altas concentraciones de SARS-CoV-2 a los alveolos exige que los AM fagociten una carga inusual de virus altamente patógenos, lo que resulta en la síntesis y liberación de IL-1, IL-6 y TNF. De esa forma, se inicia la cascada inflamatoria y el reclutamiento de neutrófilos a los espacios alveolares (Rubins, 2013). Los cambios metabólicos inducidos por la inflamación contribuyen a la disbiosis, complicando aún más el cuadro clínico (Huffnagle et al., 2017).

La activación excesiva de AM y la consiguiente inflamación pulmonar pueden contribuir a la tormenta de citoquinas sistémica que se presenta alrededor de los 9 días post inicio de síntomas en algunos casos graves de infección por SARS-CoV-2, fenómeno que puede estar asociado a la estimulación dependiente de anticuerpos (ADE), la cual involucra a anticuerpos no neutralizantes del tipo IgG inducidos por la infección en el epitelio bronquial y la respuesta de BALT. Los virus activos, unidos a los anticuerpos IgG no neutralizantes, pueden entrar y replicarse en DC y macrófagos presentadores de antígenos y amplificar el proceso inflamatorio (Felsenstein et al., 2020).

Los procesos inflamatorios crónicos, aun los de bajo grado, aumentan el riesgo de COVID-19 severo, como lo ejemplifica la obesidad (Cai et al., 2020; Sattar et al., 2020), en la que se ha demostrado alta producción y circulación de TNF, IL-1B, IL-6 y CRP, activación permanente de macrófagos (Muscogniuri et al., 2020) y respuesta deficiente contra influenza (Green \& Beck, 2017). Petrakis y colaboradores (2020) publicaron una excelente revisión de las consecuencias inmunológi- cas de la obesidad y su contribución a la severidad de COVID-19.

La contaminación del aire por elementos químicos y partículas también causa inflamación pulmonar crónica y afecta la salud cardiaca y pulmonar (Künzli \& Tager, 2005; Liu et al., 2009). La mortalidad por la COVID-19 en Estados Unidos es mayor en los condados con mayor contaminación del aire (X. Wu et al., 2020). Este estudio no encontró asociación con consumo de cigarrillos. El impacto de la contaminación del aire domiciliar con humo de cigarrillos sobre la incidencia de infecciones respiratorias, incluyendo en niños preescolares de Guatemala, está bien documentada (Cruz et al., 1990). Fumar tabaco causa inflamación pulmonar aguda y crónica (van der Vaart et al., 2005) e induce la expresión de ACE2 en las células epiteliales. El interferón e infecciones virales incrementan los niveles de ACE2 en la superficie de las células respiratorias (Smith et al., 2020). Las lesiones cardiacas, vasculares, renales, hepáticas y neurológicas en COVID-19 parecen también tener una génesis inflamatoria (Ammirati \& Wang, 2020; Li et al., 2020; Ronco \& Reis, 2020; Subbarao \& Mahaanty, 2020; Sultan et al., 2020; Zubair et al., 2020).

La respuesta inmune adaptativa y específica contra SARS-CoV-2 puede resultar en procesos inflamatorios severos cuando los individuos se enfrentan de nuevo al virus en etapas posteriores a la fase aguda de la infección inicial. Se ha propuesto que el síndrome multisistémico inflamatorio en niños y jóvenes (MIS-C), que se inicia con síntomas leves de COVID-19 alrededor de 25 días después del inicio de la enfermedad, es causado por el fenómeno ADE, con la participación de anticuerpos IgG anti-SARSCoV-2, neutrófilos y mastocitos que responden a una exposición secundaria al virus (Ricke et al., 2020). Es también posible que la ADE se inicie por anticuerpos inespecíficos producidos previamente por infecciones debidas a uno de los coronavirus estacionales (Berard et al., 2020) o por la inmunización pasiva (Dzik, 2020; Sullivan \& Roback, 2020).

Resulta de sumo interés que los anticuerpos IgG anti SARS-CoV-2 producidos por individuos que tuvieron síntomas leves, parecen ser de corta vida media (Ibarrondo et al., 2020). Es posible que las defensas de las mucosas de estos pacientes, incluyendo a los anticuerpos SIgA, hayan evitado infecciones severas de las vías respiratorias inferiores y promovido la producción de anticuerpos IgG con baja afinidad y duración. Es posible, sin embargo, que anticuerpos del tipo IgM sean protectores. La observación que las personas 
Tabla 2

Infección por SARS-CoV-2 y proporción de grupos sanguíneos en donantes de sangre, áreas sanitarias de Guatemala

\begin{tabular}{lccccc}
\hline \multirow{2}{*}{ Región Sanitaria } & Incidencia & \multicolumn{3}{c}{ Grupo Sanguíneo $^{1}$} \\
\cline { 3 - 6 } & SARS-CoV-2 & $\mathrm{O}$ & $\mathrm{A}$ & $\mathrm{B}$ & $\mathrm{AB}$ \\
\hline I Central & 1009.02 & 73.41 & 17.93 & 7.78 & 0.87 \\
IV Sur & 296.23 & 74.05 & 16.30 & 8.56 & 1.11 \\
III Oriente & 352.54 & 75.58 & 17.29 & 6.42 & 0.71 \\
II Occidente & 209.32 & 86.06 & 8.66 & 4.86 & 0.43 \\
V Norte & 99.10 & 88.40 & 8.71 & 2.82 & 0.07 \\
\hline
\end{tabular}

Nota. ${ }^{1}$ Fuente de datos: Ministerio de Salud Pública y Asistencia Social, 2020b. Coeficiente Spearman de Correlación Incidencia/Grupo $\mathrm{O}, \mathrm{rs}=-0.9000, \mathrm{p}(2$ colas $)=0.03739)$

Tabla 3

Prevalencia (\%) de sintomas de COVID-19

\begin{tabular}{lcccc}
\hline \multirow{2}{*}{ Síntoma } & \multicolumn{3}{c}{ Referencia } \\
\cline { 2 - 5 } & $\begin{array}{c}\text { Rodríguez-Morales } \\
\text { et al., 2020 }\end{array}$ & Siordia et al., 2020 & Yang et al., 2020 & Grant et al., 2020 \\
\hline Fiebre & 88.7 & 82.2 & 85.5 & 78.0 \\
Adultos & 92.8 & & & \\
Niños & 43,9 & & 58.0 & 57.0 \\
Tos & 57.6 & 61.7 & & \\
Adultos & 63.4 & & 14.5 & 23.0 \\
Niños & 22.0 & 41.0 & 32.0 & 34.0 \\
Disnea & 45.6 & 44.0 & 22.0 & 17.0 \\
Fatiga & 29.4 & 22.7 & & 12.0 \\
Mialgia & & 27.7 & 13.0 & 13.0 \\
Producción de esputo & 28.5 & 15.1 & 13.5 & 10.0 \\
Dolor de garganta & 11.0 & 6.7 & 7.0 & 6.0 \\
Dolor de cabeza & 8.0 & 8.4 & 2.0 & 4.0 \\
Diarrea & 6.1 & 9.4 & & 4 \\
Nausea & & 3.6 & & \\
Vómitos & & 2.2 & & \\
Dolor abdominal & & & & \\
Rigor y escalofrío & & & & \\
\hline & & & & \\
\hline
\end{tabular}


con grupo sanguíneo $\mathrm{O}$, tengan menor susceptibilidad a COVID-19 (Zhao et al., 2020; Zietz \& Tatonetti., 2020) (Tabla 2) correlaciona con los hallazgos genéticos (Ellinghaus et al., 2020b) y fortalece la hipótesis que los anticuerpos naturales tipo IgM dirigidos contra los determinantes galactosados del grupo sanguíneo A neutralizan al SARS-CoV-2, atacando su envoltura después de completar la replicación (Breinan et al., 2020).

\section{Conclusiones}

Desarrollar síntomas y la severidad de la COVID-19 parecen asociados a la forma en que el virus SARS-CoV-2 llega a las vías respiratorias inferiores y a la respuesta inflamatoria que resulta de la replicación viral en las células epiteliales de tráquea y alveolos. La infección por vía nasal muy probablemente ayuda a disminuir la carga viral que pueda alcanzar la laringe, la tráquea y los alveolos, mientras permite la producción de anticuerpos del tipo SIgA, que resultan protectores de todas las mucosas, estabilizan el microbioma y limitan la posibilidad de respuesta inflamatoria excesiva, como la potencialmente provocada por anticuerpos del tipo IgG. El análisis de la expresión genética y funcional del sistema innato de defensas en respuesta a SARS-Cov-2 ha demostrado que la cinética y la intensidad de la producción de mediadores protectores son significativamente mayores en el epitelio nasal que en el bronco-alveolar (Pizzorno et al., 2020). Este escenario permite sugerir que, como se ha propuesto para el virus de la influenza (Ainai et al., 2020), la vacunación por vía intranasal es la más indicada para prevenir las infecciones por SARSCoV-2 y la COVID-19 grave. Mientras se encuentra una vacuna efectiva y segura, las medidas preventivas deberán seguir enfocándose en la conducta humana. El diagnóstico temprano de infección por SARS-CoV-2, el manejo adecuado de los síntomas iniciales y de los procesos inflamatorios tempranos de COVID-19 son vitales para evitar enfermedad severa y muerte.

\section{Agradecimientos}

A Benjamín Wizel, por sugerencias para el contenido. A Omar Dary y Francisco Villagrán de León, por ayuda editorial.

\section{Referencias}

Agarwal, A., Chen, A., Ravindran, N., To, C., \& Thulivath, P. J. (2020). Gastrointestinal and liver manifestations of COVID-19. Journal of Clinical and Experimental Hepatology, 10(3), 263-265. https://doi.org/10.1016/j.jceh.2020.03.001

Ainai, A., van Riet E., Ito, R., Ikeda, K., Senchi, K., Suzuki, T., ... Hasegawa, H. (2020). Human immune responses elicited by an intranasal inactivated H5 influenza vaccine. Microbiology and Immunology, 64(4), 313-325. https://doi. org/10.1111/1348-0421.12775

Amarante-Mendes, G. P., Adjemian, S., Branco L. M., Zanetti, L., Weinlich, R. \& Bortoluci, K. R. (2018). Pattern recognition receptors and the host cell death molecular machinery. Frontiers in Immunology, 9, 2379. https://doi.org/10.3389/ fimmu.2018.02379.

Ammirati, E., \& Wang, D. W. (2020). SARS-CoV-2 inflames the heart. The importance of awareness of myocardial injury in COVID-19 patients. International Journal of Cardiology, 311, 122123. https://doi.org/10.1016/j.ijcard.2020.03.086

Arons, M. M., Hatfield, K. M., Reddy, S. C., Jacobs, J. R., Taylor, J., Spicer, K., ... Jernigan, J. A. (2020). Presymptomatic SARS-CoV-2 infection and transmission in a skilled nursing facility. New England Journal of Medicine, 382, 2081-2090. https://doi.org/10.1056/NEJMoa2008457

Berard, R. A., Scuccimari, R., Haddad, E. M., Morin, M.P., Chan, K., ... Acute Care Committee. (Jul 6, 2020). Paediatric inflammatory multisystem syndrome temporally associated with COVID-19. Canadian Paediatric Society. https://www.cps.ca/ en/documents/position/pims

Berger, A. (2000). Th1 and Th2 responses. What are they? British Medical Journal, 321(7258), 424. https://doi.org/10.1136/bmj.321.7258.424

Brann, D. H., Tsukahara, T., Weinreb, C, Lipovsek, M., Van den Berge, K., Gong, B., ... Datta, S. R. (2020). Non-neuronal expression of SARSCoV-2 entry genes in the olfactory systems suggests mechanisms underlying COVID-19 associated anosmia. bioRxiv. https://doi. org/10.1101/2020/03.25.009084 
Breiman, A., Ruven-Clouet, R., \& Le Pendu, J. (2020). Harnessing the natural anti-glycan immune response to limit the transmission of enveloped viruses such as SARS-CoV-2. PLoS Pathogens, 16, 21008556. https://doi.org/10.1371/journal. ppat.1008556.

Byambusaren, O., Cardona M., Bell., K., Clark, J., McLaws M.-L., \& Glasziou, P. (2020). Estimating the extent of asymptomatic COVID-19 and its potential for community transmission: Systematic review and meta-analysis. medRxiv. https://doi. org $/ 10.1101 / 2020.05 .10 .20097543$

Cai, Q., Chen, F., Wang, T., Luo, F., Liu, X., Wu, Q., ... $\mathrm{Xu}, \mathrm{L}$. (2020). Obesity and COVID-19 severity in a designated hospital in Shenzhen, China. Diabetes Care, 43(7), 1392-1398. https://doi. org $/ 10.2337 / \mathrm{dc} 20-0576$.

Centers for Disease Control and Prevention. (2020a). Multisystem Inflammatory Syndrome in Children (MIS-C) Associated with Coronavirus Disease 2019 (COVID-19). https://emergency.cdc. gov/han/2020/han00432.asp

Centers for Disease Control and Prevention. (2020b). Public Health Screening to Begin in 3 US Airports for 2019 Novel Coronavirus ("2019-nCoV"). https://www.cdc.gov/media/releases/2020/p0117coronavirus-screening.html

Centers for Disease Control and Prevention. (2020c). Testing in High-Density Critical Infrastructure Workplaces. https://www.cdc. gov/coronavirus/2019-ncov/community/workersafety-support/hd-testing.html

Chan, J. F.-W., Yuan, S., Kok, K-H., Chu, H., Yang, J., Xing, F., .. Yuen, K.-Y. (2020). A familial cluster of pneumonia associated with the 2019 novel coronavirus indicating person-to-person transmission: A study of a family cluster. Lancet, 395(10223), 514-523. https://doi.org/10/1016/ S0140-6736(20)30154-9

Cheng, H.-Y., Jian, S.-W., Liu, D.-P., Ng, T.-C., Huang, W.-T., Lin, H.-H., \& Taiwan COVID-19 Outbreak Investigation Team. (2020). Contact tracing assessment of COVID-19 transmission dynamics in Taiwan and risk at different exposure periods before and after symptom onset. JAMA Internal Medicine, 180(9), 1156-1163. https://doi. org/10.1001/jamainternmed.2020.2020.
Chou, R., Dana, T., Buckely, D. I., Selph, S., Fu, R., \& Totten, A. M. (2020). Epidemiology of and risk factors for Coronavirus infection in health care workers. Annals of Internal Medicine, 173(2), 120-136. https://doi.org/10.7326/M20-1632

Corthésy, B. (2013). Multi-faceted functions of secretory $\operatorname{IgA}$ at mucosal surfaces. Frontiers in Immunology, 4, Article 185. https://doi. org/10.3389/fimmu.2013.00185.

Cruz, J. R., Pareja, G., de Fernández, A., Peralta, F., Cáceres, P., \& Cano, F. (1990). Acute respiratory tract infections among Guatemalan ambulatory preschool children. Reviews on Infectious Diseases, 12 (suppl 8), S1029-S1034. https://doi. org/10.1093/clinids/12.supplement_8.s1029

Davies, N. G., Klepac, P., Liu, Y., Prem, K., Jit, M., CMMID COVID-19 Working Group, \& Eggo, R. M. (2020). Age-dependent effects in the transmission and control of COVID-19 epidemics. Nature Medicine, 26, 1205-1211 https://doi.org/10.1038/s41591-020-0962-9

Davies, J., \& Davies D. (2010). Origins and evolution of antibiotic resistance. Microbiology and Molecular Biology Reviews, 74(3), 417-433. https://doi.org/10.1128/MMBR.00016-10

Debertin, A. S., Tschernig, T., Tonjes, H., Kleemann, W. J., Troger, H. D., \& Pabst, R. (2003). Nasalassociated lymphoid tissue (NALT): Frequency and localization in young children. Clinical \& Experimental Immunology, 134(3), 503-507. https://doi.org/10.1111/j.1365-2249.2003.02311.x

De Giorgi, V., Recalcati, S., Jia, Z., Chong, W., Ding, R., Deng, Y., ... Lotti, T. (2020). Cutaneous manifestations related to coronavirus disease 2019 (COVID-19): A prospective study from China and Italy. Journal of the American Academy of Dermatology, 83(2), 674-675. https:// doi.org/10.1016/j.jaad.2020.05.073.

Dickson, R. P., Erb-Downward, J. R., Martinez, F. J., \& Huffnagle, G. B. (2016). The microbiome and the respiratory tract. Annual Reviews of Physiology, 78, 481-504. https://doi.org/10.1146/annurevphysiol-021115-105238

Divani, A. A., Andalib, S., Di Napoli, M., Lattanzi, S., Hussain, M. S., Biller, J., ... Torbey, M. (2020). Coronavirus disease 2019 and stroke: Clinical manifestations and pathophysiological 
insights. Journal of Stroke and Cerebrovascular Diseases, 29(8), 104941. https://doi.org/10.1016/j. strokecerebrovasdis.2020.104941.

Domingo, J. L., Marques, M., \& Rovira, J. (2020). Influence of airborne transmission of SARSCoV-2 on COVID-19 pandemic. A review. Environmental Research, 188, $109861 \mathrm{https://}$ doi.org/10.1016/j.envres.2020.109861

Dyal, J. W., Grant, M. P. Broadwater, K., Bjork, A., Waltenburg M. A., Gibbson, D. D., ... Honein, M. A. (2020). COVID-19 among workers in meat and poultry processing facilities - 19 States, April 2020. Morbidity and Mortality Weekly Report, 69(18), 557-561. https://doi.org/10.15585/mmwr. $\mathrm{mm} 6918 \mathrm{e} 3$

Dzik, S. (2020). COVID-19 convalescent plasma: Now is the time for better science. Transfusion Medicine Reviews, 34(3), 141-144. https://doi. org/10.1016/j.t,rv.2020.04.002.

Ellinghaus, D., Degenhardt, F., Bujanda, L., Buti, M., Albillos, A., Invernizzi, P., ... The Severe Covid-19 GWAS Group. (2020a). Genomewide association study of severe Covid-19 with respiratory failure. New England Journal of Medicine. https://doi. org/10.1056/NEJMoa2020283.

Ellinghaus, D., Degenhardt, F., Bujanda, L., Buti, M., Albillos, A., Invernizzi, P., Karlsen, T. H. (2020b). The ABO blood group locus and a chromosome 3 gene cluster associate with SARS$\mathrm{CoV}-2$ respiratory failure in an Italian-Spanish genome-wide association analysis. medRxiv. https://doi.org/10.1101/2020.05.31.20114991.

Fahy, J. V., \& Dickey, B. F. (2010). Airway mucus function and dysfunction. New England Journal of Medicine, 363(23), 2233-2247.https://doi. org/10.1056/nejmra0910061

Feldstein, L. R., Rose, E. B., Horwitz, S. M., Collins, J. P. Newhams, M. M., Son, M. B., ... Randolph, A. G. (2020). Multisystemic inflammatory syndrome in U.S. children and adolescents. New England Journal of Medicine, 383, 334-346. https://doi. org/10.1056/NEJMoa2021680.

Felsenstein, S., Herbert, J. A., McNamara, P. S., \& Hedrich, C. M. (2020). COVID-19: Immunology and treatment options. Clinical Immunology, 215, 108448 https://doi.org/10.1016/j.clim.2020.108448.
Garrett, K., Kamdar, A. A., \& Stark, J. M. (2019). Lung defenses: Intrinsic, innate, and adaptive. En R. W. Wilmott, R. Deterding, A. Li, F. Ratjen, P, Sly, H. J. Zar \& A. Bush (Eds.), Kendig's disorders of the respiratory tract in children ( ( $^{\text {th }}$ ed., pp. 120-133). Elsevier. https://doi.org/10.1016/c2015-0-1292-8.

Global News. (March 3, 2020). Coronavirus: Here's a timeline of COVID-19 cases in Canada. https:// globalnews.ca/news/6627505/coronavirus-covidcanada-timeline/

Gon, Y., \& Hashimoto, S. (2018). Role of airway epithelial barrier dysfunction in pathogenesis of asthma. Allergology International, 67, 12-17. https://doi.org/10.1016/j.alit.2017.08.011

Grant, M. C., Geoghegan, L., Arbyn, M., Mohammed, Z., McGuiness, L., Clarke, E. L., \& Wade, R. G. (2020). The prevalence of symptoms in 24,410 adults infected with the novel coronavirus (SARS-CoV-2; COVID-19): A systematic review and meta-analysis of 148 studies from 9 countries. PLoS One, 15, e0234765. https://doi. org/10.1371/journal.pone.0234765.

Green, W. D., \& Beck, M. A, (2017). Obesity altered $\mathrm{T}$ cell metabolism and the response to infection. Current Opinion on Immunology, 46, 1-7. https:// doi.org/10.1016/j.coi.2017.03.008

Gupta, A., Madhavan, M. V., Sehgal, K., Nair, N., Mahajan, S, Sehrawat, T. V., ... Landry, D. W. (2020). Extrapulmonary manifestations of COVID-19. Nature Medicine, 26, 1017-1032. https://doi.org/10.1038/s41591-020-0968-3

Hajifathalian, K., Kristo, T., Mehta, A., Kumar, S., Schwartz, R., Fortune, B., \& Sharaiha, R. (2020). Gastrointestinal and hepatic manifestations of 2019 novel coronavirus disease in a large cohort of infected patients from New York: Clinical implications. Gastroenterology. https://doi. org/10.1053/j.gastro.2020.05.010.

Hammer, L., Dubbed, P., Capron, I, Ross, A., Jordan, A., Lee, J., ... Leibrand, H. (2020). High SARS $\mathrm{CoV}-2$ attack rate following exposure at a choir practice - Skagit County, Washington, March 2020. Morbidity and Mortality Weekly Report, 69(19), 606-610. http://doi.org/10.15585/mmwr. mm6919e6

Hanshew, A. S., Jette, M. E., Rosen, S. P., \& Thibeault, 
S. L. (2017). Integrating the microbiota of the respiratory tract with the unified airway model. Respiratory Medicine, 126, 68-74. https://doi. org/10.1016/j.rmed.2017.03.019

He, X., Lau, E. H., Wu, P., Deng X.; Wang, J., Hao, X., ... Leung, G. M. (2020). Temporal dynamics in viral shedding and transmissibility of COVID-19. Nature Medicine, 26, 672-675. https://doi. org/10.1038/s-41591-020-0869-5.

Hiemstra, P. S., McGray, P. B., \& Bals, R. (2015). The innate immune function of airway epithelial cells in inflammatory lung disease. European Respiratory Journal, 45(4), 1150-1162. https:// doi.org/10.1183/09031936.00141514

Hou, Y., Okuda, K., Edwards, C. E., Martinez, D. R., Asakura, T., Dinnon, K. H., ... Baric, R. S. (2020). SARS-CoV-2 reverse genetics reveals a variable infection gradient in the respiratory tract. Cell, 182(2), 429-446. https://doi.org/10.1016/j. cell.2020.05.042

Huang, C., Wang, Y., Li, X., Ren, L. Zhao, J., Zhang, L., ... Cao, B. (2020). Clinical features of patients infected with 2019 novel coronavirus in Wuhan, China. Lancet, 395(10223), 497-506. https://doi. org/10.1016/S0140-6736(20)30183-5.

Huang, Y., Chen, S., Yang, Z., Guan, W., Liu, D., Lin, Z., ... Li, Y. (2020). SARS-CoV-2 viral load in clinical samples from critically ill patients. American Journal of Respiratory and Critical Care Medicine, 201(11), 1435-1438. https:/doi. org/10.1164/rccm.202003-0572LE

Hui, K. P. Y., Cheung, M.-C., Perera R. A. P. M., Ng, K.-C., Bui, C. H. T., Ho, J. C. W., ... Chan, M. C. W. (2020). Tropism, replication competence, and innate immune responses of the coronavirus SARS-CoV-2 in human respiratory tract and conjunctiva: an analysis in ex-vivo and invitro cultures. Lancet Respiratory Medicine, 8(7), 687-695. https://doi.org/10.1016/S22132600(20)30193-4

Huffnagle, G. B., Dickson, R. P., \& Lukacs, N. W. (2017). The respiratory tract microbiome and lung inflammation: a two-way street. Mucosal Immunology, 10(2), 299-306. https://doi. org/10.1038/mi.2016.108

Ibarrondo, F. J., Fulcher, J. A., Goodman-Meza, D.,
Elliott, J., Hoffman, C., Hausner, M. A., ... Yang, O. O. (2020). Rapid decay of anti-SARS-CoV-2 antibodies in persons with mild Covid-19. New England Journal of Medicine, 383, 1085-1087. https://doi.org/10.1056/NEJMc2025179.

International Committee for Taxonomy of Viruses. (2020). Naming the 2019 Coronavirus. https:// talk.ictvonline.org/information/w/news/1300/page Invernizzi, R., Lloyd, C. M., \& Molyneaux, P. L. (2020). Respiratory microbiome and epithelial interactions shape immunity in the lung. Immunology, 160(2), 171-182. https://doi. org/10.1111/imm.13195

Jang, S., Han, S. H., \& Rhee, J.-Y. (2020). Cluster of Coronavirus disease associated with fitness dance classes. Emerging Infectious Diseases Journal, 26(8), 1917-1920. https://doi.org/10.3201/ eid2608.200633.

Jegaskanda, S., Weinfurter, J. T., Friedrich, T. C., \& Kent, S. J. (2013). Antibody-dependent cellular cytotoxicity is associated with control of pandemic H1N1 influenza virus infection of macaques. Journal of Virology, 87(10), 55125522. https://doi.org/10.1128/JVI.03030-12

Johns Hopkins University. (2020). COVID-19 Data Repository by the Center for Systems Science and Engineering (CSSE) at Johns Hopkins University. Recuperado de https://coronavirus. jhu.edu/map.html

Kato, A., \& Scheieimer, R. P. (2007). Beyond inflammation: Airway epithelial cells are at the interface of innate and adaptive immunity. Current Opinion in Immunology, 19(6), 711-720. https://doi.org/10.1016/j.coi.2007.08.004

Kikkert, M. (2020). Innate immune evasion by human respiratory RNA viruses. Journal of Innate Immunity, 12, 4-20. https://doi. org/10.1159/000503030

Khan, N., de Manuel, M., Peyregne, S., Do, R., Prufer, K., Marques-Bonet, T., ...Varki, A. (2020). Multiple genomic events altering hominin SIGLEC Biology and innate immunity predated the common ancestor of humans and archaic hominins. Genome Biology and Evolution, 12(7), 1040-1050. https://doi.org/10.1093/gbe/evaa125

Künzli, N., \& Tager, I. B. (2005). Air pollution: From 
lung to heart. Swiss Medical Weekly, 135(47-48), 697-702.

Klompas, M., Baker, M. A., \& Rhee, C. (2020). Airborne transmission of SARS-CoV-2. Theoretical considerations and available evidence. Journal of the American Medical Association, 324(5), 441442. https://doi.org/10.1001/jama.2020.12458.

Lai, C.-C., Ko, W.-C., Lee, P.-I., Jean, S.-S., \& Hsueh, P.-R. (2020). Extra-respiratory manifestations of COVID-19. International Journal of Antimicrobial Agents, 56(2), 106024. https://doi. org/10.106/j.ijantimicag.2020.106024.

Lambrecht, B. N., Neyt, K., \& van Helden, M. J. (2015). The mucosal immune response to respiratory viruses. En J. Mestecky, W. Stober, M. Russell, H. Cheroutre, B. N. Lambrecht \& B. Kelsall (Eds.), Mucosal immunology (4 ${ }^{\text {th }}$ ed., pp. 18051815). Elsevier.

Lavezzo, E., Franchin, E., Ciavarella, C., CuomoDanneburg, G., Barzon, L., Del Vecchio C., ... Cristanti, A. (2020). Suppression of COVID-19 outbreak in the municipality of Vo, Italy. medRxiv. https://doi.org/10.1101/2020.04.17.20053157.

Li, J.-W., Han, T.-W., Woodward, M., Anderson, C. S., Zhou, H., Chen, Y.-D., \& Neal, B. (2020). The impact of 2019 novel coronavirus on heart injury: A systematic review and meta-analysis. Progress in Cardiovascular Diseases , 63, 518-524. https:// doi.org/10.1016/jcad2020.04.008.

Lin, L. K., Suzuki, Y., Nakano, H., Ramsburg, E., \& Gunn, M. D. (2008). CCR2 monocyte-derived dendritic cells and exudate macrophages produce influenza-induced pulmonary immune pathology and mortality. Journal of Immunology, 180(4), 2562-2572. https://doi.org/10.4049/ jimmunol.180.4.2562

Liu, L., Poon, R., Chen, L., Frescura, A.-M., Montuschi, P., Ciabattoni, G., ... Dales, R. (2009). Acute effects of air pollution on pulmonary function, airway inflammation, and oxidative stress in asthmatic children. Environmental Health Perspectives, 117, 668-674. https://doi. org/10.1289/ehp11813

Luo, L. Liu, D., Liao, X.-I., Wu, X.-B., Jing, Q.-X., Zheng, J.-Z., ... Mao, C. (2020). Modes of contact and risk of transmission in COVID-19 among close contacts. medRxiv. https://oi.org/10.1101/
2020.03.24.20042606.

Lyadova, I. V., \& Panteleev, A. V. (2015). Th1 and Th17 cells in tuberculosis: Protection, pathology, and biomarkers. Mediators of Inflammation, 2015, ID 854507. https://doi.org/10.1155/2015/854507.

Madjid, M., Safavi-Naeini P., Solomon, S. D., \& Vardeny, O. (2020) Potential effects of Coronavirus on the cardiovascular system. A review. JAMA Cardiology, 5(7), 831-840. https:// doi.org/10.1001/jamacardio.2020.1286

Mantis, N. J., Rol, N., \& Corthesy, B. (2011). Secretory IgA's complex roles in immunity and mucosal homeostasis in the gut. Mucosal Immunology, 4(6), 603-611.

Menni, C., Sudre, C. H., Steves, C. J., Ourselin, S., \& Spector, T. D. (2020). Quantifying additional COVID-19 symptoms will save lives. Lancet, 395(10241), e107-e108. https://doi.org/10.1016/ S0140-6736(20)31281-2

Menni, C., Valdes, A. M., Freidin, M. B, Sudre, C. H., Nguyen, L. H, Drew, D. A., \& Spector, T. D. (2020). Real-time tracking of self-reported symptoms to predict potential COVID-19. Nature Medicine, 26(7), 1037-1040. https://doi. org/10.1038/s41591-020-0916-2

Ministerio de Salud Pública y Asistencia Social de Guatemala. (2020a). Situación de COVID-19 en Guatemala. Casos confirmados por laboratorio. https://tablerocovid.mspas.gob.gt/

Ministerio de Salud Pública y Asistencia Social de Guatemala. (2020b). Expediente UNIP-906-2020. Unidad de Información Pública del Ministerio de Salud y Asistencia Social. Enviado al autor el 15 de junio 2020

Mizumoto, K., Kagaya K., Zarebski, A., \& Chowell, G. (2020). Estimating the asymptomatic proportion of coronavirus diseases 2019 (COVID-19) cases on board the Diamond Princess Cruise ship, Yokohama, Japan, 2020. European Surveillance. 25(10), 2000180. https://doi.org/10.2807/15607917.ES.2020.25.10.2000180

Muscogniuri, G., Pugliese, G., Barrera, L., Savastano, S., \& Colao, A. (2020). Commentary: Obesity: The "Achilles heel" for COVID-19. Metabolism, 108, 154251. https://doi.org/10/1016/j. metabol.2020.154251.

Mustafa, N. A., \& Selim, L. A. (2020). Characterisation 
of COVID-19 pandemic in paediatric age group: A systematic review and meta-analysis. Journal of Clinical Virology,128, 104395. https://doi. org/10.1016/j.jcv.2020.104395.

Nishiura, H., Linton, N. M., \& Akhetzhanov, A. R. (2020). Serial interval of novel coronavirus (COVID-19) infections. International Journal of Infectious Diseases, 93, 284-286. https://doi. org/10.1016/j.ijid.2020.02.060

Pabst, O., Cerovic, V \& Honef, M. (2016). Secretory IgA in the coordination of establishment and maintenance of the microbiota. Trends in Immunology, 37(5), 287-296. https://doi. org/10.1016/j.it.2016.03.002

Pan, D., Sze, S., Minhas, J., Bangash, M. N., Pareek, N., Divall, P., ... Pareek, M. (2020). The impact of ethnicity on clinical outcomes in COVID-19: A systematic review. EClinicalMedicine, 23, 100404. https://doi.org/10.1016/j. cinm2020.100404.

Patwa, A., \& Shah, A. (2015). Anatomy and physiology of the respiratory system relevant to anaesthesia. Indian Journal of Anaesthesia, 59(9), 533-541. https://oi.org/10.4103/0019-5049.165849

Petersen, C., \& Round, J. L. (2014). Defining dysbiosis and its influence on host immunity. Cellular Microbiology, 16(4), 1024-1033. https://doi. org/10.1111/cmi.12308

Petrakis, D., Margină, D., Tsarouhas, K., Tekos, F., Stan, M., Nikitovic, D., ... Tsatsakis, A. (2020). Obesity - a risk factor for increased COVID-19 prevalence, severity, and lethality (Review). Molecular Medicine Reports, 22, 9-19. https:// doi.org/10.3892/mmr.2020.11127

Pizzorno, A., Padey, B., Julien, T., Trouillet-Assant, S., Traversier, A., Rosa-Calatrava, M. (2020). Characterization and treatment of SARS-CoV-2 in nasal and bronchial human airway epithelia. Cell Reports Medicine, 1(4), 100059. https://doi. org/10.1016/j.xcrm.2020.100059.

Randall, T. D. (2015). Structure, organization, and development of the mucosal immune system of the respiratory tract. En J. Mestecky, W. Stober, M. Russell, H. Cheroutre, B. N. Lambrecht \& B. Kelsall (Eds.), Mucosal immunology (4th ed., pp. 43-61). Elsevier.

Rezaee, F., Meednu, N., Emo, J. A., Saatian, B.,
Chapman T. J., ... Georas, S. N. (2011). Polyinosinic: polycytidylic acid induces protein kinase D-depended disassembly of apical junctions and barrier dysfunction in airway epithelial cells. Journal of Allergy and Clinical Immunology, 128(6), 1216-1224. https://doi. org/10.1016/j.jaci.2011.08.035

Ricke, D. O., Gherlone, N., Fremont-Smith, P., Tisdall, P., \& Fremont-Smith, M. (2020). Kawasaki disease and multisystem inflammatory syndrome in children: Antibody-induced mast cell activation hypothesis. Journal of Pediatrics and Pediatric Medicine, 4(2), 1-7.

Riphagen, S., Gomez, X., Gonzalez-Martinez, C., Wilkinson, N., \& Theocharis, P. (2020). Hyperinflammatory shock in children during COVID-19 pandemic. Lancet, 395(10237), 1607-1608. https://doi.org/10.1016/S01406736(20)31094-1

Rodríguez-Morales, A. J., Cardona-Ospina, J. A., Gutiérrez-Ocampo, E., Villamizar-Pena, R., Holguín-Rivera, Y., Escalera-Antezana, J. P., ... Sah, R. (2020). Clinical, laboratory and imaging features of COVID-19: A systematic review and meta-analysis. Travel Medicine and Infectious Disease, 34, 101623. https://doi.org/10.1016/j. tmaid.2020.101623.

Ronco, C., \& Reis, T. (2020). Kidney involvement in COVID-19 and rational for extracorporeal therapies. Nature Reviews, 16(6), 308-310. https:// doi.org/10.1038/s41581-020-0284.7.

Rubins, J. B. (2013). Alveolar macrophages. Wielding the double-edged sword of inflammation. American Journal of Respiratory and Critical Care Medicine, 167(2), 103-104. https://doi. org/10.1164/rccm.2210007.

Sardanelli, F., Cozzi, A., Manfardini, L., Bnà, C., Foà, R. A., Spinazzola, A., Schiaffino, S. (2020). Association of mediastinal lymphadenopathy with COVID-19 prognosis. Lancet Infectious Diseases, 20, 1230-1231. https://doi.org/10.1016/ S1473-3099(20)30521-1.

Sattar, N., McInnes, I. B., \& McMurray, J. J. V. (2020). Obesity is a risk factor for severe COVID-19 infection: Multiple potential mechanism. Circulation, 142(1), 4-6. https://doi.org/10.1161/ 
circulationaha.120.047659.

Schuster, B. S., Suk, J. S., Woodworth, G. F., \& Hanes, J. (2013). Nanoparticle diffusion in respiratory mucus from humans without lung disease. Biomaterials, 34(13), 3439-3446. https://doi. org/10.1016/j.biomaterials.2013.01.064

Segal, L. N., Alekseyenko, A. V., Clemente, J. C., Kulkarni, R., Wu, B., Chen, H., ... Weiden, M. D. (2013). Enrichment of lung microbiome with supraglottic taxa is associated with increased pulmonary inflammation. Microbiome, 1(1), 19. https://doi.org/10.1186/2049-2618-1-19

Sharma, G., Volgman, A. S., \& Michos, E. D. (2020). Sex differences in mortality from COVID-19 pandemic: Are men vulnerable and women protected? Journal of the American College of Cardiology, 2(9), 1407-1410. https://doi. org/10.1016/j.caccas.2020.04.027.

Silva-Sánchez, A., \& Randall, T. D. (2020). Anatomical uniqueness of the mucosal immune system (GALT, MALT, iBALT) for the induction and regulation of mucosal immunity and tolerance. En H. Kiyono \& D. W. Pascual (Eds.), Mucosal Vaccines (2 ${ }^{\text {nd }}$ ed., pp. 21-54). Academic Press. https://doi.org/10.1016/B978-0-12-8119242.00002-X

Siordia, J. A. (2020). Epidemiology and clinical features of COVID-19: A review of current literature. Journal of Clinical Virology, 127, 104357. https:// doi.org/10.1016/j.cv.2020.104357.

Smith, J. C., Sausville, E. L., Girish, V., Yuan, M. L., Vasudevan, A., John, K. M., \& Shetzer, J. M. (2020). Cigarette smoke exposure and inflammatory signaling increase the expression of the SARS-CoV-2 receptor ACE2 in the respiratory tract. Developmental Cell, 53(8), 514529. https://doi.org/10.1016/j.devcel.2020.05.012

Stark, J. M., \& Colasurdo, G. M. (2006). Lung defenses: Intrinsic, innate, and adaptative. En V. Chernick, T. F. Boat, R. W. Wilmort \& A. Bush (Eds.), Kendig's disorders of the respiratory tract in children (7 $7^{\text {th }}$ ed., pp. 205-223). Elsevier. https:// doi.org/10.1016/B978-0-7216-3695-5-50016-X.

Subbarao, K., \& Mahanty, S. (2020). Respiratory virus infections: Understanding COVID-19. Immunity, 52(6), 905-909. https://doi.org/10.106/j. immuni.2020.05.004).

Sullivan, H. C., \& Roback, J. D. (2020). Convalescent plasma: Therapeutic hope or hopeless strategy in the SARS-CoV-2 pandemic. Transfusion Medicine Reviews, 34(3), 145-150. https://doi. org/10.1016/j.tmrv.2020.04.001.

Sultan, S., Lim, J. K., Altayar. O., Davitkov, P., Feuerstein, J. D., Siddique, S. M., ... El-Serag, H. B. (2020). AGA apid recommendations for gastrointestinal procedures during the COVID-19 pandemic. Gastroenterology, 159(2), 739-758. https://doi.org/10.1053.j.gastro.2020.03.072.

Sungnak, W., Huang, N., Bécavin, C., Berg, M., Queen, R., Litvinukova, M., ... HCA Lung Biological Network (2020). SARS-CoV-2 entry factors are highly expressed in nasal epithelium cells together with innate immune genes. Nature Medicine, 26(5), 681-687. https://doi.org/10.1038/ s41591-020-0868-6.

Szatmary, P., Arora, A., Raraty, M. G. T., Dunne D. F. J., Baron, R. D., \& Halloran, C. M. (2020). Emerging phenotype of SARS-CoV-2 associated pancreatitis. Gastroenterology, 159, 1551-1554. https://doi.org/10.1053/j.gastro.2020.05.069

Takeuchi, O., \& Akira, S. (2020). Pattern recognition receptors and inflammation. Cell, 140, 805-820. https://doi.org/10.1016/j.cell.2010.01.022

The City, New York. (2020). NYC Subway Crews Hit Hardest by Coronavirus, MTA Numbers Show. 1 June 2020

Toubiana, J., Poirault, C., Corsia, A., Bajolle, F., Fourgeaud, J., Agoulvant, F... \& Allali, S. (2020). Kawasaki-lie multisystem inflammatory syndrome in children during the covid-19 pandemic in Paris, France: Prospective observational study. British Medical Journal, 369, m2094. https://doi.org/101136/bmj/m2094.

United States Environmental Protection Agency. (2009). Metabolically derived human ventilation rates revised approached based upon oxygen consumption rates (Final Report, 2009). https://cfpub.epa.gov/ncea/risk/recordisplay. cfm?deid $=202543$

van der Vaart, H., Postma, D., Timens, W., Hylkema, M. N., Willemse, B. W. M., Boezen, H. M., ... ten Hacken, N. H. (2005). Acute effects of cigarette 
smoking on inflammation in healthy intermittent smokers. Respiratory Research, 6, 22. https://doi. org/10.1186/1465-9921-6-22.

Verdoni, L., Mazza, A., Gervasoni, A., Martelli, L., Ruggeri, M., Ciuffreda, M., ... D’Antiga, L. (2020). An outbreak of severe Kawasaki-like disease at the Italian epicentre of the SARSCoV-2 epidemic: An observational cohort study. Lancet. 395(10239), 1771-1778. https://doi. org/10.1016/S0140-6736(20)31103-X.

Viner, R. M... \& Whittaker, E. (2020). Kawasakilike disease: emerging complication during the COVID-19 pandemic. Lancet, 395, 1741-1743. https://doi.org/10.1016/S0140-6736(20)31129-6.

Weber, F. (2020). Antiviral innate immunity. Introduction. Reference Module in Life Sciences. https://doi:10.1016/8978-0-12-809633-8.21290-9.

World Healt Organization. (28 February 2020a). Coronavirus disease 2019 (COVID-19). Situation Report-39. https://www.who.int/docs/defaultsource/coronaviruse/situation-reports/20200228sitrep-39-covid-19.pdf?sfvrsn=5bbf3e7d_4

World Healt Organization. (31 March 2020b). Coronavirus disease 2019 (COVID-19). Situation Report-71. https://www.who.int/docs/defaultsource/coronaviruse/situation-reports/20200331sitrep-71-covid-19.pdf?sfvrsn $=4360 \mathrm{e} 92 \mathrm{~b} \& 8$

World Healt Organization. (21 January 2020c). Novel Coronavirus (2019-nCoV) Situation Report-1. https:/apps.who.int/iris/bitstream/ handle/10665/330760/nCoVsitrep21Jan2020-eng. pdf? sequence $=3 \&$ is Allowed $=y$

World Healt Organization. (23 January 2020d). Novel Coronavirus (2019-nCoV) Situation Report-39. https://www.who.int/docs/default-source/ coronaviruse/situation-reports/20200123-sitrep3-2019-ncov.pdf?sfvrsn=d6d23643_8

Wu, X., Nehery, R. C., Sabath, B. M., Braun, D., \& Dominici, F. (2020). Exposure to air pollution and COVID-19 mortality in the United States: A nationwide cross-sectional study. medRxiv. https://doi.org/10.1101/2020/04.05/20054502.

Wu, Y., Jing, W. Liu, J, Ma, Q., Yuan, J., Wang, Y., ... Liu, M. (2020). Effects of temperature and humidity on the daily new cases and new deaths of COVID-19 in 166 countries. Science of the Total Environment, 729, 139051. https://doi. org/10.1016/j.scitotenv.2020.139051.

Wiley, J. A., Tighe, M. P., \& Harmsen, A. G. (2005). Upper respiratory tract resistance to influenza infection is not prevented by the absence of either nasal-associated lymphoid tissue or cervical lymph nodes. Journal of Immunology. 175(5), 3186-3196.

Yang, L., Liu, J., Zhang, R., Mingwu, L., Li, Z., Zhou, X., ... Lei, Y. (2020). Epidemiological and clinical features of 200 hospitalized patients with corona virus disease 2019 outside Wuhan, China. A descriptive study. Journal of Clinical Virology, 129, 104475. https://doi.org/10.1016/j. jcv.2020.104475

Zaidi, A. A., Brooke, C. M., Claes, P., McEcoy, B., Hughes, C., \& Shriver, D. (2017). Investigating the case of the human nose shape and climate adaptation. PLoS Genetics, 13(3), 21006916. https://doi.org/10.100.1371/journal.pgen.1006616.

Zanin, M., Baviskar, P., Webster, R., \& Webby, R. (2016). The interaction between respiratory pathogens and mucus. Cell Host \& Microbe, 19(2), 159-168. https://doi.org/10.1016/j. chom.2016.01.001.

Zhang, Y., Geng, X., Tan, Y., Li, Q., Xu, Q., Xu, J., ... Wang, H. (2020). New understanding of the damage of SARS-CoV-2 infection outside the respiratory system. Biomedicine \& Pharmacology, 127, 127, 110195. https://doi. org/10.1016/j.biopha.2020.110.110195.

Zhao, J., Yang, Y., Huang, H., Li, D., Gu, D. Lu, X., ... Wang, P. G. (2020). Relationship between the ABO blood group and the COVID-19 susceptibility. medRxiv. https://doi.org/10.1101/ 2020.03.11.20031096.

Zhou, R., To, K. K.-W., Wong, Y.-C., Liu, L., Zhou, B., ... Chen, Z. (2020). Acute SARS-CoV-2 infection impairs dendritic and $\mathrm{T}$ cell responses. Immunity, 53, 864-877. https://doi.org/10.1016/ jimmuni.2020.07.026.

Zhu, M. \& Fu, Y. (2012). Proinflammatory IL17 induces iBALT development. Cellular \& Molecular Immunology, 9, 101-102. https://doi. org/10.1038/cmi.2011.46. 
Zhu, N., Zhang, D., Wang, W., \& Li, X. (2020). A novel coronavirus from patients with pneumonia in China, 2019. New England Journal of Medicine, 382(8), 727-733. https://doi.org/10.1056/ NEJMoa2001017.

Zietz, M. \& Tatonetti, N. P. (2020). Testing the association between blood type and COVID-19 infection, intubation, and death. medRxiv. https://doi.org/10.1101/2020.04.08.20058073.
Zou, L., Ruan, F., Huang, M., Liang, L., Huanhy, H., Hong, Z., ... Wu, J. (2020). SARS-CoV-2 viral load in upper respiratory specimens of infected patients. New England Journal of Medicine, 383(12), 1177-1179. https://doi.org/10.1056/ NEJMc2001737.

Zubair, A. S., McAlpine, S., Gardin, T., Farhadian, S., Kuruvilla, D. E., \& Spudich, S. (2020). Neuropathogenesis and neurologic manifestations of the coronaviruses in the age of coronavirus disease 2019. JAMA Neurology, 77(8), 1018-1027. https://doi.org/10.1001/jamaneurol.2020.2065. 